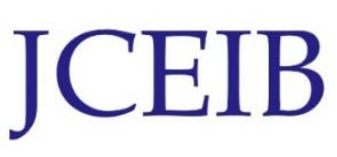

Journal of Chemical Engineering and Industrial Biotechnology (JCEIB)

ISSN: 0126-8139 (Online); Open Access

Volume 4 Issue 4 pp. 52-59; September 2018

OUniversiti Malaysia Pahang Publisher

DOI: https://doi. org/10.15282/JCEIB .V4.06.30/9/2018.4.4

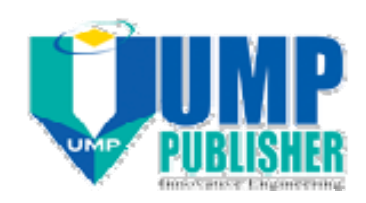

\title{
GC-MS ANALYSIS OF BIOACTIVE CONSTITUENTS OF JASMINE FLOWER
}

\author{
Hesham Hussein Rassem*, Abdurahman Hamid Nour, Rosli Mohammed Yunus \\ Faculty of Chemical and Natural Resources Engineering, Universiti Malaysia Pahang (UMP), Lebuhraya \\ Tun Razak, 26300 Gambang, Pahang, Malaysia \\ * Corresponding author: hesham_rassem@yahoo.com \\ Tel.: +601128232371 Fax.: +6095493190
}

\begin{abstract}
Gas Chromatography-Mass Spectrometry (GC-MS) the best technique to identified the compounds of essential oils by comparison of mass spectra data obtained from the sample with that taken from pure commercially available standards injected under the same conditions. To characterize the chemical constituents of Hibiscus Flower using GC-MS, the shade dried flower powder was extracted with methanol by using Microwave-assisted Hydrodistillation (MAHD). The GC-MS analysis provided different peaks determining the presence of ten compounds. These compounds have biological activity namely 2-Phenylthiolane (57.31\%), Cyclohexene, 3-ethenyl(25.91\%), Acetaldehyde (12.70\%), N-Methylallylamine (9.99\%), Propanamide $(6.79 \%)$ and Phthalic acid, bis (7-methyloctyl) ester (5.21\%). From the results, it can be concluded that Jasmine flower extract shows the presence of 10 phytocompounds. The presence of various bioactive compounds justifies the use of the jasmine flower for various ailments by traditional practitioners.
\end{abstract}

Keywords: Microwave-Assisted Hydrodistillation (MAHD); Gas ChromatographyMass Spectrometry (GC-MS); Phytochemical constituents; Methanol extract

\subsection{INTRODUCTION}

Jasmine tree was originated from tropical countries such as Africa, Australia, and Southeast Asia. Currently, Jasmine trees are grown all over the world. In the present study, essential oils extracted from local Jasmine flowers in Malaysia such as Melati and Melur were investigated. The essential oil of Jasmine exhibits the essence of flavor and aroma of Jasmine flower. Its properties are dependent on the types of glycerides and hydrocarbon. Essential oils of Jasmine flower have been extensively used as an expectorant (for dry skin), antiseptic, antispasmodic and antidepressant (Mojay, 1999). Also, these essential oils are used to cure depression, exhaustion, sensitive skin, headache, and cough (Lawless, 2013). 
These are several species of Jasmine, out of several varieties, Jasmine sambac, Jasmine auriculatum, and Jasmine grandiflorum are used industrially for essential oil production (Green \& Miller, 2009). In this study, Jasmine grown in Malaysia was explored.

In the extraction of Jasmine oil, different extraction methods had been employed which include hydrodistillation, solvent extraction, and maceration. Nevertheless, the methods had been reported to suffer some drawbacks which include lower yield of oil (Reverchon, 1997; Zizovic, Stamenić, Orlović, \& Skala, 2007). However, to an outcome this drawback, Microwave-Assisted Hydrodistillation (MAHD) technique was employed for recovering oil from Jasmine flower.

Microwave-Assisted Hydrodistillation (MAHD) is one of the popular techniques used in extracting biological compounds because it offers the solvent selectivity. Also, it is able to shorten the extraction time and control the heating process. MAHD is environmentally friendly as it emits less $\mathrm{CO}_{2}$ (Lucchesi, Chemat, \& Smadja, 2004) and it is more efficient than the conventional steam distillation process (Farhat, Ginies, Romdhane, \& Chemat, 2009). This technique has been used to extract many bioactive components from plants (Golmakani \& Rezaei, 2008). In general, its efficiency is mainly dependent on the dielectric constants of solvent and sample (Brachet, Christen, $\&$ Veuthey, 2002). Conventional techniques used to extract bioactive compounds are time-consuming and they are unable to control the heating process. Also, the analysis of constituents in plant material is restricted by extraction step (Mandal, Mohan, \& Hemalatha, 2007).

Thus, this study investigated the extraction of oil from Jasmine flower using Microwave-Assisted Hydrodistillation (MAHD) technique and the chemical compositions of the extracted oil at the optimal conditions were examined using gas chromatography-mass spectrometry (GC-MS).

\subsection{MATERIALS AND METHODS}

\subsection{Collection and preparation sample}

The fresh Jasmine flowers were purchased from (Nature Flower Enterprise), Pahang, Malaysia in April 2016. The flowers were washed with water in order to remove the impurities. The flowers were dried in an oven operating at $90{ }^{\circ} \mathrm{C}$ for $1 \mathrm{~h}$ to reduce the moisture content to $10.0-12.5 \%$. The dried flowers were then grinded by using (Grinder Ultra Centrifugal Mill ZM 200, Retsch, Germany) in order to increase the area of contact between the solvent and the flower (powdered form). After grinding, the samples were sieved using a mechanical sieve shaker to obtain $80 \mu \mathrm{m}$ size of jasmine flowers powder. Methanol (Fisher Scientific) was used as solvent and dichloromethane (Fisher Scientific) was used to separate the essential oils from methanol.

\subsection{Extraction Method}

The microwave oven (Milestone MWS Ethos E Solvent Extraction System: 2.5KW; $230 \mathrm{~V}-60 \mathrm{~Hz} ; 2450 \mathrm{MHz}$ ) was modified for the current MAHD operation. Jasmine flowers of $35 \mathrm{~g}$ were put in a 1L flask with $280 \mathrm{ml}$ methanol. The flask was heated in the microwave oven. The microwave oven was operated by power $400 \mathrm{~W}$ for 120 minutes (Rassem, Nour, \& Yunus, 2017). The essential oil in the flask evaporated and the vapors were passed to the condenser (Clevenger device). The extract, i.e. mixture of methanol and essential oil was collected and put into the separating funnel with dichloromethane for separation purpose. The yield of the essential oil, i.e. $0.89 \%(\mathrm{v} / \mathrm{w})$ 
was calculated on a dry weight basis. The yield of oil that obtained was calculated by using Equation (1):

$$
\text { Yteld of essenttal otl }=\frac{\text { Amount of essnttal out }(g)}{\text { Amount of raw matertals }(g)}
$$

\subsection{GC-MS analysis}

The Agilent 5975C Series GC/MSD used in the current analysis employed a fused silica column packed with DB-WAX $(30 \mathrm{~mm} \times 0.25 \mathrm{~nm} \mathrm{ID} \times 2.5 \mu \mathrm{m})$ and $100 \%$ dimethyl poly siloxane. The operating oven temperature was set as $60{ }^{\circ} \mathrm{C}$ for $10 \mathrm{~min}$ and increased at a rate of $20{ }^{\circ} \mathrm{C} / \mathrm{min}$ to attain $250{ }^{\circ} \mathrm{C}$ (held for $10 \mathrm{~min}$ ). The helium gas speed $30 \mathrm{~cm} / \mathrm{s}$ was employed.

\subsection{Identification of components}

Identification was based on the molecular structure, molecular mass and calculated fragments. Interpretation on mass spectrum GC-MS was conducted using the database of National Institute Standard and Technology having more than 62,000 patterns. The name, molecular weight and structure of the components of the test materials were ascertained. The relative percentage amount of each component was calculated by comparing its average peak area to the total areas. The spectrum of the unknown component was compared with the spectrum of the component stored in the NIST library version (2005).

\subsection{Analysis with Fourier transform infrared spectroscopy (FTIR)}

Analyses were performed by using Thermo Scientific Nicolet iS5 FT-IR Spectrometer. The spectrum has been recorded for wave numbers ranging between $4000 \mathrm{~cm}^{-1}$ and 400 $\mathrm{cm}^{-1}$ and the functional groups in the essential oil for jasmine flower were identified.

\subsection{RESULTS AND DISCUSSION}

GC-MS is one of the best techniques to identify the constituents of volatile matter, long chain, branched chain hydrocarbons, alcohols acids, esters etc. The GC-MS analysis of jasmine flower revealed the presence of ten compounds (phytochemical constituents) that could contribute the medicinal quality of the plant. The identification of the phytochemical compounds was confirmed based on the peak area, retention time and molecular formula. Figure 1 shows the results of the present study. The compound prediction was performed based on NIST Database. The identified compounds were 2Phenylthiolane (57.31\%), Cyclohexene, 3-ethenyl- (25.91\%), Acetaldehyde (12.70\%), N-Methylallylamine (9.99\%), Propanamide (6.79\%), Phthalic acid, bis(7-methyloctyl) ester (5.21\%), 10-Methylnonadecane (2.25\%), (Aminomethyl) cyclopropane $(0.79 \%)$, 1H-Tetrazol-5-amine (0.49\%) and 1,2-Benzenedicarboxylic acid diisooctyl ester $(0.37 \%)$. As shown in Table 1 , the Retention Times (RTs) of ten major components are 6.253, 33.029, 40.656, 45.090, 45.587, 50.118, 50.850, 56.001, 58.499 and 60.371, respectively. The phytochemicals identified through GC-MS analysis showed many biological activities relevant to this study are listed in Table 2 . The biological activities 
listed are based on Dr. Duke's Phytochemical and Ethnobotanical Databases created by Dr. Jim Duke of the Agricultural Research Service/USDA. The functional groups in the essential oil were identified via FT-IR. As can be seen from these spectra, there is an overlap of the absorption spectrum of each of the different components of the oil. This is due to the mixture complexity of volatile oils. The region from 4000 to $400 \mathrm{~cm}^{-1}$ is highly informative as the peaks for the characteristic fingerprint of jasmine flowers oil lie within this range. The functional groups present in the essential oil were determined by comparing the vibration frequencies in wave numbers of the sample spectrograph obtained from an FT-IR spectrophotometer with those of an IR correlation chart. As observed from the FT-IR spectrum, the absorption bands or frequencies of $3286.39 \mathrm{~cm}^{-1}$ and $2920.65 \mathrm{~cm}^{-1}$ show the presence of $\mathrm{O}-\mathrm{H}$ stretch for phenol and C-C stretch, respectively. Meanwhile, the absorbance band of $1627.08 \mathrm{~cm}^{-1}$ reveals the presence of $\mathrm{C}=\mathrm{O}$ bond for aldehyde. The formation of the peak at $1304.70 \mathrm{~cm}^{-1}$ is due to ring stretching. The peak at $1151.75 \mathrm{~cm}^{-1}$ corresponds to $\mathrm{C}-\mathrm{O}$ stretching vibration. The peak at $767.11 \mathrm{~cm}^{-1}$ is an attribute of a vibrational characteristic of benzene ring absorption of $\mathrm{C}=\mathrm{H}$ group. Some important peaks and their representations are reported in Table 3 and Figure 2.

Table 1: Components detected in the plant of methanol extract of Jasmine flowers

\begin{tabular}{clcccc}
\hline No & \multicolumn{1}{c}{ Compounds } & $\begin{array}{c}\text { Molecular } \\
\text { Formula }\end{array}$ & MW & RT & Area\% \\
\hline 1 & Acetaldehyde & $\mathrm{C}_{2} \mathrm{H}_{4} \mathrm{O}$ & 44.05 & 6.253 & 12.70 \\
2 & 2-Phenylthiolane & $\mathrm{C}_{10} \mathrm{H}_{12} \mathrm{~S}$ & 164.26 & 33.029 & 57.31 \\
3 & Propanamide & $\mathrm{C}_{3} \mathrm{H}_{7} \mathrm{NO}$ & 73.09 & 40.656 & 6.79 \\
4 & (Aminomethyl)cyclopropane & $\mathrm{C}_{4} \mathrm{H}_{9} \mathrm{~N}$ & 71.12 & 45.090 & 0.74 \\
5 & Cyclohexene, 3-ethenyl & $\mathrm{C}_{8} \mathrm{H}_{12}$ & 108.18 & 45.587 & 25.91 \\
6 & N-Methylallylamine & $\mathrm{C}_{4} \mathrm{H}_{9} \mathrm{~N}$ & 71.12 & 50.118 & 9.99 \\
7 & 1H-Tetrazol-5-amine & $\mathrm{C}_{8} \mathrm{H}_{12} \mathrm{O}$ & 390.55 & 50.850 & 0.49 \\
8 & 1,2-Benzenedicarboxylic acid, diisooctyl ester & $\mathrm{C}_{24} \mathrm{H}_{38} \mathrm{O}_{4}$ & 124.18 & 55.999 & 0.37 \\
9 & 10-Methylnonadecane & $\mathrm{C}_{20} \mathrm{H}_{42}$ & 282.54 & 58.499 & 2.25 \\
10 & Phthalic acid, bis(7-methyloctyl) ester & $\mathrm{C}_{26} \mathrm{H}_{42} \mathrm{O}_{4}$ & 418.61 & 60.371 & 5.21 \\
\hline
\end{tabular}




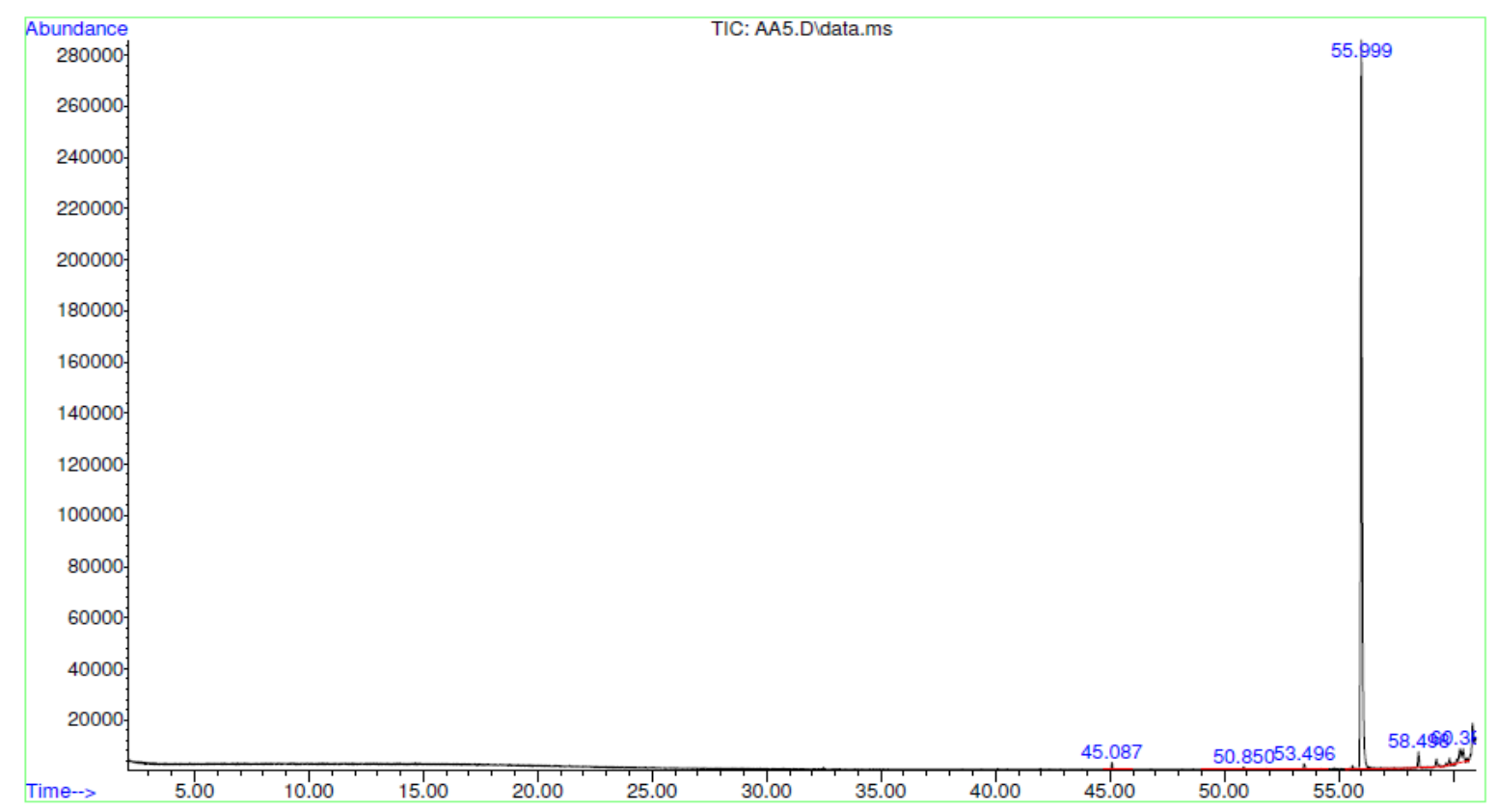

Figure 1: GC-MS Chromatogram of Methanolic extract of Jasmine flower

Table 2: Activity of Phyto-Components identified in the methanol extracts of Jasmine flowers.

\begin{tabular}{|c|c|c|c|}
\hline No & Compounds & $\begin{array}{l}\text { Molecular } \\
\text { Formula }\end{array}$ & $* *$ Activity \\
\hline 1 & Acetaldehyde & $\mathrm{CH}_{3} \mathrm{CHO}$ & $\begin{array}{l}\text { Antioxidant, } \\
\text { Cancer preventive. }\end{array}$ \\
\hline 2 & 2-Phenylthiolane & $\mathrm{C}_{10} \mathrm{H}_{12} \mathrm{~S}$ & $\begin{array}{l}\text { Antioxidant, } \\
\text { Hypocholesterolemic, } \\
\text { Antimicrobial. }\end{array}$ \\
\hline 3 & Propanamide & $\mathrm{C}_{3} \mathrm{H}_{7} \mathrm{NO}$ & $\begin{array}{l}\text { Antioxidant, } \\
\text { Pesticide, } \\
\text { Cancer preventive. }\end{array}$ \\
\hline 4 & (Aminomethyl)cyclopropane & $\mathrm{C}_{4} \mathrm{H}_{9} \mathrm{~N}$ & $\begin{array}{l}\text { Antioxidant, } \\
\text { Antimicrobial. }\end{array}$ \\
\hline 5 & Cyclohexene, 3-ethenyl & $\mathrm{C}_{8} \mathrm{H}_{12}$ & $\begin{array}{l}\text { Antioxidant, } \\
\text { Antimicrobial. }\end{array}$ \\
\hline 6 & N-Methylallylamine & $\mathrm{C}_{4} \mathrm{H}_{9} \mathrm{~N}$ & $\begin{array}{l}\text { Antioxidant, } \\
\text { Cancer preventive. }\end{array}$ \\
\hline 7 & 1H-Tetrazol-5-amine & $\mathrm{C}_{8} \mathrm{H}_{12} \mathrm{O}$ & Antioxidant. \\
\hline 8 & $\begin{array}{l}\text { 1,2-Benzenedicarboxylic acid, } \\
\text { diisooctyl ester }\end{array}$ & $\mathrm{C}_{24} \mathrm{H}_{38} \mathrm{O}_{4}$ & $\begin{array}{l}\text { Antioxidant, } \\
\text { Anemiagenic, }\end{array}$ \\
\hline 9 & 10-Methylnonadecane & $\mathrm{C}_{20} \mathrm{H}_{42}$ & $\begin{array}{l}\text { Antioxidant, } \\
\text { Cancer preventive Antimicrobial. }\end{array}$ \\
\hline 10 & Phthalic acid, bis(7-methyloctyl) ester & $\mathrm{C}_{3} \mathrm{H}_{6} \mathrm{~N}_{6}$ & $\begin{array}{l}\text { Antioxidant, } \\
\text { Cancer preventive. }\end{array}$ \\
\hline
\end{tabular}

**Activity source: Dr. Duke's Phytochemical and Ethnobotanical Database 
Table 3: FT-IR spectral analysis functional theory calculations studies

\begin{tabular}{ccc}
\hline NO. & $\begin{array}{c}\text { Vibration } \\
\text { assignment }(\boldsymbol{v}) \\
\left(\mathbf{c m}^{-\mathbf{1}}\right)\end{array}$ & Absorption band \\
\hline 1 & 3286.39 & O-H \\
2 & 2920.65 & C-C stretching \\
3 & 1627.08 & C=O stretching \\
4 & 1304.70 & Ring stretching \\
5 & 1151.75 & C-O stretching \\
6 & 1016.30 & C-OH deformation vibration \\
7 & 767.11 & $\mathrm{C}=\mathrm{H}$ vibration of benzene ring \\
8 & 518.76 & $\mathrm{C}=\mathrm{C}$ vibration of benzene ring \\
\hline
\end{tabular}

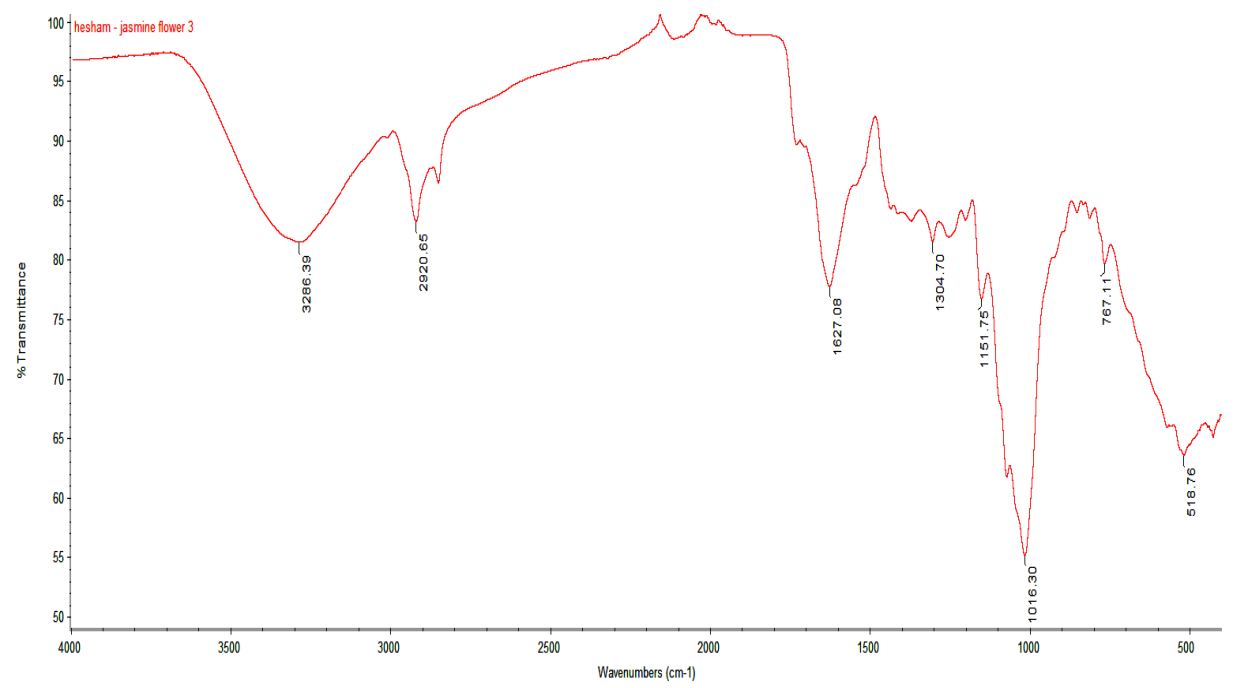

Figure 2: FT-IR spectrum of essential oil for jasmine flower

\subsection{CONCLUSION}

The source of many plants (herbs and spices) can often be identified from the peak pattern of the chromatograms obtained directly from headspace analysis. Similarly, unique qualitative and quantitative patterns from a GC analysis will often help identify the source of many alcoholic beverages. The technique of fingerprint could really identify the false herbal products. The construction of chromatographic fingerprints aims at evaluating the quality of Herbal Medicines (Liang, Xie, \& Chan, 2004). A total of ten compounds have been identified from the current GC-MS analysis performed on the methanolic extract of Jasmine flowers. The functional groups present in the essential oil were determined by comparing the vibration frequencies in wave numbers of the sample spectrograph obtained from an FT-IR spectrophotometer with those of an IR correlation chart. It was through these active groups that they verified the authenticity of 
the vehicles detected through GS-MS. Those components are 2-Phenylthiolane (57.31\%), Cyclohexene, 3-ethenyl- (25.91\%), Acetaldehyde (12.70\%), NMethylallylamine (9.99\%), Propanamide (6.79\%), Phthalic acid, bis(7-methyloctyl) ester (5.21\%), 10-Methylnonadecane (2.25\%), (Aminomethyl) cyclopropane $(0.79 \%)$, $1 \mathrm{H}$-Tetrazol-5-amine $(0.49 \%)$ and 1,2-Benzenedicarboxylic acid, diisooctyl ester $(0.37 \%)$. Therefore, GC-MS method is a direct and fast analytical approach for identification of terpenoids and steroids and only few grams of plant material is required. The importance of the study is due to the biological activity of some of these compounds. The present study, which reveals the presence of components in jasmine flower suggest that the contribution of these compounds on the pharmacological activity should be evaluated. The current GC-MS analysis is useful in extracting active principles of the medicinal plant such as Jasmine. This technique could be applied to other medicinal plants as well.

\section{ACKNOWLEDGEMENTS}

The authors would like to thank Malaysia Ministry of Education and Universiti Malaysia Pahang for providing assistance during the course of this research (PGRS grant, 160363).

\section{REFERENCES}

Brachet, A., Christen, P., \& Veuthey, J. L. (2002). Focused microwave-assisted extraction of cocaine and benzoylecgonine from coca leaves. Phytochemical Analysis, 13(3), 162-169.

Farhat, A., Ginies, C., Romdhane, M., \& Chemat, F. (2009). Eco-friendly and cleaner process for isolation of essential oil using microwave energy: experimental and theoretical study. Journal of Chromatography A, 1216(26), 5077-5085.

Golmakani, M.-T., \& Rezaei, K. (2008). Comparison of microwave-assisted hydrodistillation withthe traditional hydrodistillation method in the extractionof essential oils from Thymus vulgaris L. Food Chemistry, 109(4), 925-930.

Green, P., \& Miller, D. (2009). The genus Jasminum in cultivation: Royal Botanic Gardens.

Lawless, J. (2013). The Encyclopedia of essential oils: the complete guide to the use of aromatic oils in aromatherapy, herbalism, health, and well being: Conari Press.

Liang, Y.-Z., Xie, P., \& Chan, K. (2004). Quality control of herbal medicines. Journal of chromatography B, 812(1-2), 53-70.

Lucchesi, M. E., Chemat, F., \& Smadja, J. (2004). An original solvent free microwave extraction of essential oils from spices. Flavour and Fragrance Journal, 19(2), 134-138.

Mandal, V., Mohan, Y., \& Hemalatha, S. (2007). Microwave assisted extraction-an innovative and promising extraction tool for medicinal plant research. Pharmacognosy reviews, 1(1), 7-18.

Mojay, G. (1999). Aromatherapy for healing the spirit: Restoring emotional and mental balance with essential oils: Inner Traditions/Bear \& Co. 
Rassem, H. H., Nour, A. H., \& Yunus, R. M. (2017). GC-MS analysis of bioactive constituents of Hibiscus flower. Australian Journal of Basic and Applied Sciences, 11(3), 91-97.

Reverchon, E. (1997). Supercritical fluid extraction and fractionation of essential oils and related products. The journal of supercritical fluids, 10(1), 1-37.

Zizovic, I., Stamenić, M., Orlović, A., \& Skala, D. (2007). Supercritical carbon dioxide extraction of essential oils from plants with secretory ducts: Mathematical modelling on the micro-scale. The journal of supercritical fluids, 39(3), 338346. 